\title{
EL PROCESO DE APRENDIZAJE DEBE DARSE A CEREBRO TOTAL
}

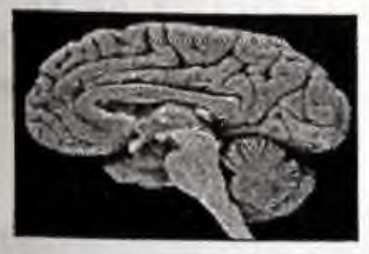

El proceso de aprendizaje debe darse explorando todas las posibilidades para que el estudiante a través de ellas logre descubrir sus reales capacidades en el camino hacia el conocimiento y el desarrollo integral.

El profesor debe tener en cuenta que cada uno de los estudiantes es un universo diferente pues los cien mil millones de neuronas que organizan el cerebro, tienen las conexiones más inesperadas, ya que a partir de su misma gestación, el encuentro con el medio donde nace y especialmente las primeras personas con quienes interactúa marcarán la conformación cerebral, con la infinidad de conexiones neurales que maduran en la niñez, a las cuales se refieren los estudiosos de las neurociencias, entre ellos el científico colombiano Rodolfo Llinás y los norteamericanos neurobióloga Carla Shatz de la Universidad de California-Berkeley, Patricia Kuhl de la Universidad de Washington y Harry Chugani neuropediatra de la Universidad del Estado de Wayne en Detrot. Ellos aseguran que conexión neural que no se logre en los primeros 10 años de vida, será muy difícil de desarrollar en la edad adulta. Esto significa que si el niño no tiene oportunidad de responder adecuadamente a los primeros retos que le impone el ritmo de vida, difícilmente va a tener la capacidad d $\epsilon$ desa:- $:$ llar nuevas estrategias inteligentes, de conocimiento y de transformación de la realidad tanto para sí mismo, como para la sociedad en que se halla inmerso.

\author{
Por Luis Humberto Alvarado Castañeda \\ Mag. Desarrollo Educativo y Social \\ Coordinador de Práctica Docente \\ Departamente de Lenguas Modernas \\ Universidad Surcolombiana
}

La educación juega un papel muy importante en el descubrimiento de las habilidades de los estudiantes, que no siempre son coincidentes. El profesor en el aula encuentra estudiantes que poco participan activamente, no les gusta salir frente al grupo, prefieren el trabajo en grupo en vez de individual, hablar en vez de escribir o la geometría en lugar de las matemáticas. El profesor a veces piensa que aquellos estudiantes que no le participan activamente pierden la asignatura sin remedio, pero hay que tener en cuenta que estilos y ritmos de aprendizaje varían de persona a persona.

Por eso, el centro educativo debe ofrecer el mayor número de técnicas y métodos para la presentación de las ideas, los contenidos, los temas, de tal manera que la variedad favorezca los diferentes estilos y ritmos de aprendizajes: Exposiciones, mesas redondas, gráficos, T.V., computador, retroproyector, trabajo en grupos, en forma individual, a través de argumentación, aprender hacierdo o ejercitando con reportes orales $y / o$ escritos, incorporando siempre la lúdica, la música y propiciando siempre el desarrollo integral de las cuatro habilidades lingüísticas, etc.

Nuestra educación siempre ha favorecido el ejercicio del hemisferio izquierdo del cerebro: la lógica, el raciocinio, las matemáticas, el análisis abstracto, la memorización etc., mientras que el derecho que es la expresión de la creatividad, del entendimiento espacial, de 
las metáforas, el de la intuición y del humanismo, está siendo dejado de lado por la mayoría de los educadores y del sistema educativo en general.

Las pruebas de ICFES, que son el pasaporte para acceder a la educación superior, sólo miden la capacidad del hemisferio izquierdo: memorización de los conceptos de ciencias, razonamiento abstracto, lógica matemática, etc., y muy poco o nada de las habilidades del hemisferio derecho.

El jóven bachiller se enfrenta al difícil reto de elegir la profesión: si no ha tenido la variedad de técnicas y métodos durante sus estudios básicos anteriores, difícilmente habrá logrado descubrir su capaciodad de acuerdo con su desarrollo derebral.

Comenzará entonces a dar palos de ciego jugando con variables que en la mayoría de los casos no le darán los resultados esperados, a menos que, gracias a su gran plasticidad (que considero otra inteligencia del ser humano) termine acomodándose y "gustándole" la profesión P que precisamente no coincide con las reales capacidades de su organización

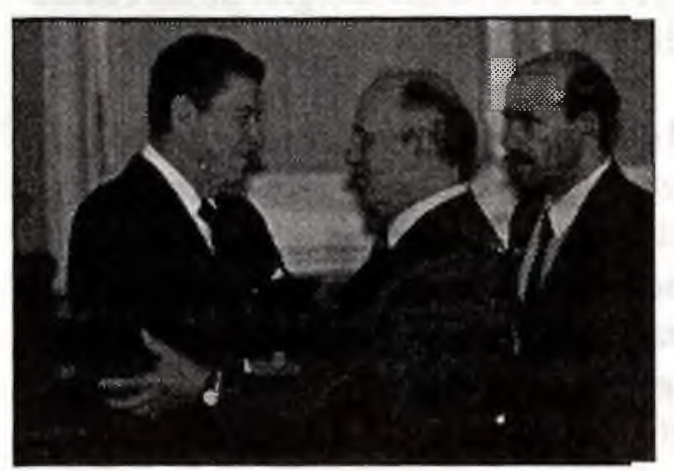

neurocerebral única. Correrá el peligro de avanzar sin mayores éxitos en su vida profesional y de sentirse haciendo algo que va en contravía de su "voluntad".

Howard Gardner (1983) en su libro sobre las estructuras mentales y las múltiples inteligencias, plantea la posibilidad de desarrollar siete inteligencias en el proceso de aprendizaje. aunque no siempre se desarrollan todas por igual. Diez años más tarde retoma su teoría y la lleva a la práctica dando pautas más precisas para su desarrollo.

En 1994 el profesor Thomas Armstrong aplica el modelo, adaptándolo para el salón de clase a través de un diseño novedoso en el curriculum escolar. En este mismo año Brian Haggerty (1994) lanza las primeras técnicas para balancear y nutrir el desarrollo de las múltiples inteligencias, en su libro "Nutriendo las Inteligencias".

En síntesis, después de definir cada una de ellas, nos proponen ejercitar las siete inteligencias así:

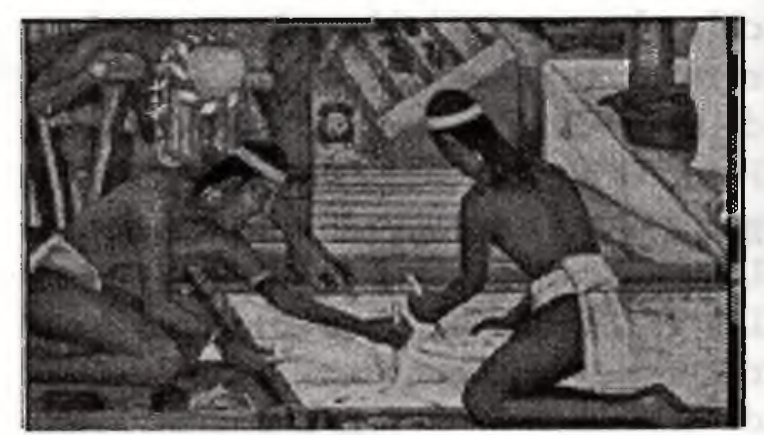

2. La Interpersonal. Interactuando con la gente y descifrando sus diversas formas de comportamiento, diferenciando rasgos de uno a otro, compartiendo con elllos sus similitudes y diferencias. 
3. La Intrapersonal. Ejercitando la introspeccion, el autoanálisis, descubriédose a sí mismo, controlando sus sentimientos, desarrollando su ternura y autoestima.
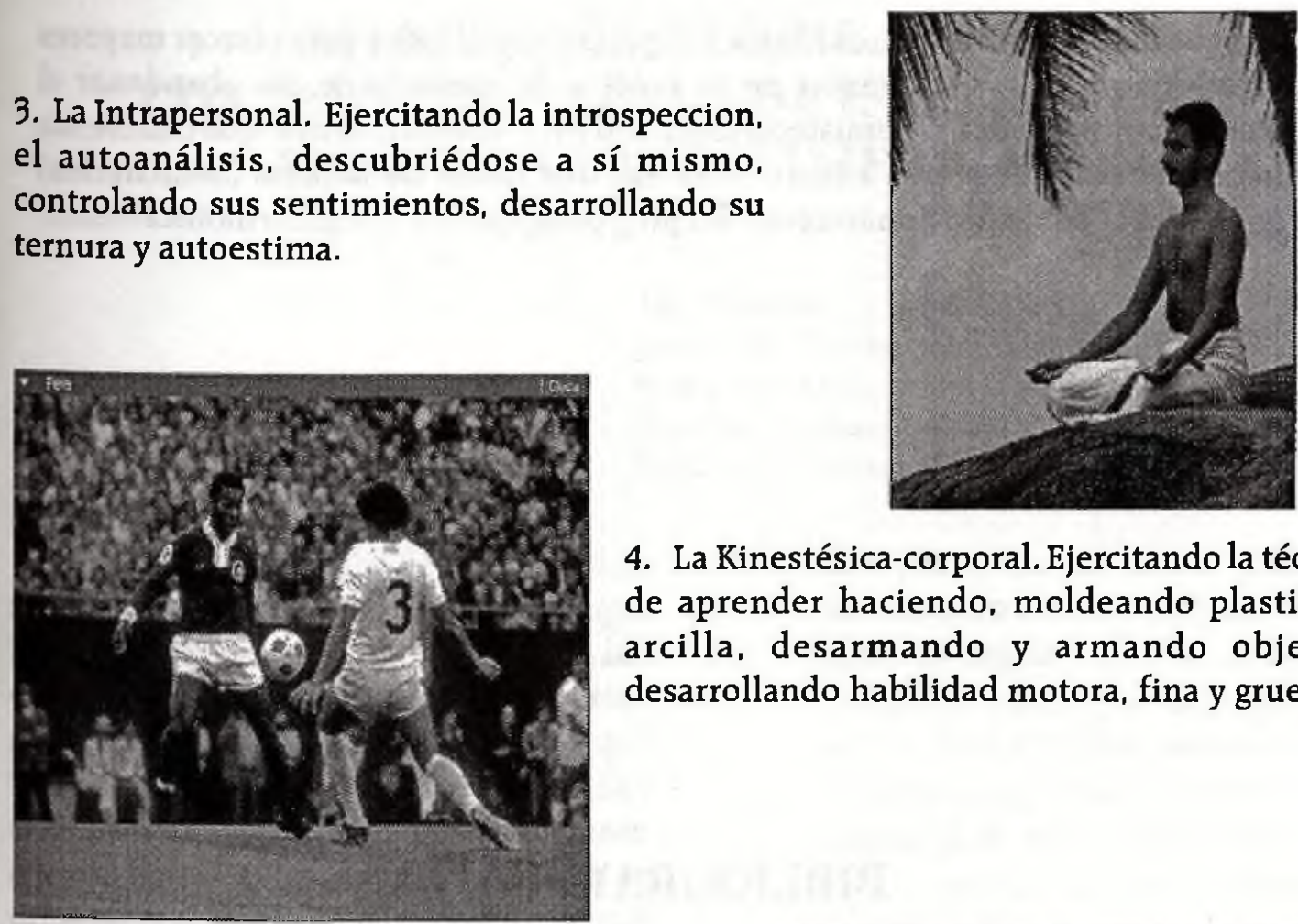

4. La Kinestésica-corporal. Ejercitando la técnica de aprender haciendo, moldeando plastilina, arcilla, desarmando y armando objetos, desarrollando habilidad motora, fina y gruesa.

5. La Lingüística. Diferenciando sonidos, significados, vocabulario, desarrollando funciones del lenguaje, ejercitando las cuatro habilidades de escuchar, hablar, leer y escribir.

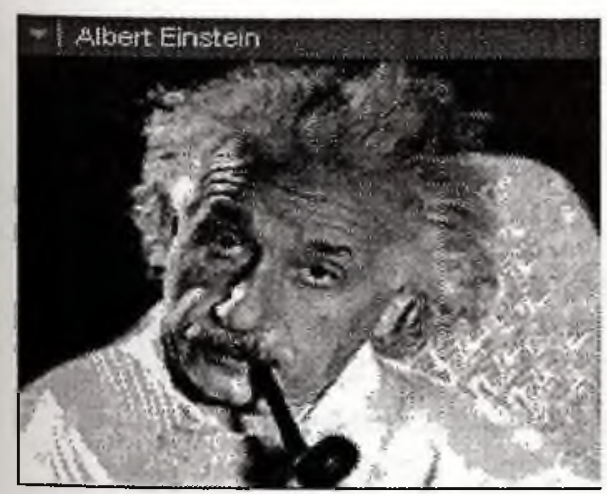

7. La Musical, Apreciando le ritmo del universo, la respiración, el canto de las aves, distinguiendo el timbre de voz de las personas como su impronta fonética, enseñándole a disfrutar, apreciar, reconocer e incluso interpretar piezas musicales de grandes compositores, facilitándole el instrumento de su agrado. símbolos.

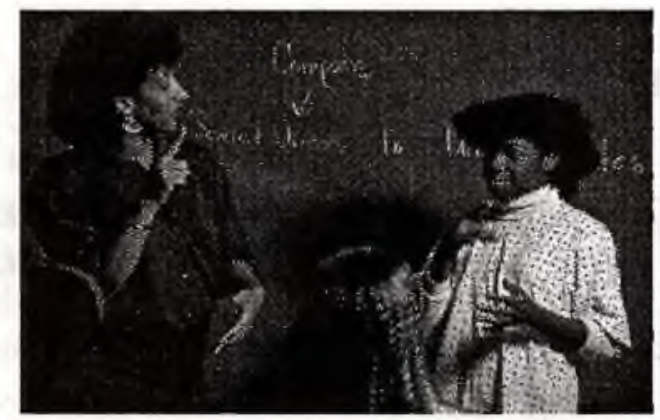

6. La Lógica Matemática. Habilidad para contar, manejo de las cuatro operaciones aritméticas, desarrollo de la habilidad para predecir y apreciar patrones de razonamiento como causa-efecto, estableciendo categorías, clasificaciones y relaciones. Razonamiento abstracto y uso de

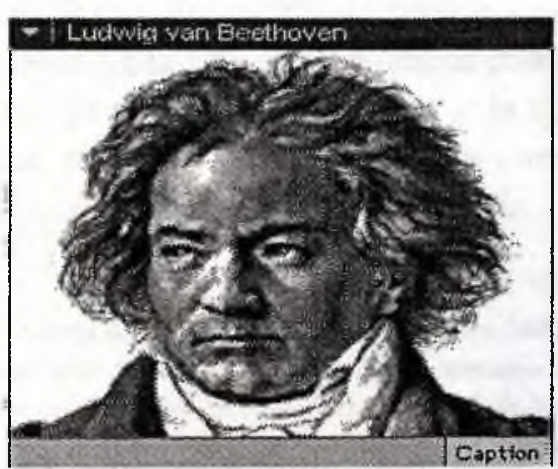

P

E

D

A 
Espero que estas reflexiones nos lleven a depertar inquietudes para ofrecer mayores oportunidades a nuestros estudiantes en su proceso de aprendizaje, sin abandonar el "rigor" académico, que marca al hemisferio izquierdo ni la "chispa creativa" que caracteriza al hemisferio derecho. Es poner a funcionar los dos lados de la mesa (hemisferios) donde se realliza el doble funcionamiento del ping pong que los integra armónicamente.

\section{BIBLIOGRAFÍA}

1. ARMSTRONG, Thomas. Múltiple intelligences in the classroom. Alexandra, Virginia. USA. Association for Supervision and Curriculum Development.

2. CHUGANI, Harry. Reporte de avance científico de investigación neuropediátrica. Universidad de Wayne, Detroit, USA 1996.

3. GARDNER, Howard. Frames of mind: the theory of multiple intelligences. New York, 1983.

4. Multiple intelligences: the theory in practice. New York, 1993.

D

5. HAGGERTY, Brian. Nurturing intelligences. Menlo Park, California, Addison.

G

6. KUHL, Patricia. El desarrollo neurobiológico del niño. Universidad de Washington, 1995.

7. LLINAS, Rodolfo. Las neurociencias. Revista de Investigaciónes científicas. 